\title{
Socioeconomic and Clinical Factors Are Key To Uncovering Disparity in Accrual Onto Therapeutic Trials for Breast Cancer
}

\author{
Carolyn E. Behrendt, $\mathrm{PhD}^{\mathrm{a}}$; Arti Hurria, $\mathrm{MD}^{\mathrm{b}}$; Lusine Tumyan, $\mathrm{MD}^{c}$; Joyce C. Niland, $\mathrm{PhD}^{\mathrm{a}}$; and \\ Joanne E. Mortimer, MD
}

\begin{abstract}
To monitor and address disparity in accrual, patient participation in cancer clinical trials is routinely summarized by race/ethnicity. To investigate whether confounding obscures racial/ethnic disparity in participation, all women with breast cancer treated by medical oncologists at City of Hope Comprehensive Cancer Center from 2004 through 2009 were classified by birthplace and self-reported race/ethnicity, and followed for accrual onto therapeutic trials through 2010. Undetectable on univariate analysis, significantly reduced participation by subjects of African, Asian, Eastern European, Latin American, and Middle Eastern ancestries was revealed after accounting for age, socioeconomic factors, tumor and oncologist characteristics, and intrapractice clustering of patients. ( $J$ Natl Compr Canc Netw 2014;12:1579-1585)
\end{abstract}

Diversity among clinical research subjects is essential for ensuring that trial results are generalizable to the full population of patients. ${ }^{1}$ In addition, trial participation may provide direct benefit to patients, who as subjects may receive more comprehensive care and access to experimental treatments not otherwise available. For these reasons, cancer centers routinely monitor disparity in accrual onto therapeutic trials by race/ethnicity and gender. This monitoring

From the Departments of anformation Sciences, ${ }^{b}$ Medical Oncology, and 'Diagnostic Radiology, City of Hope Comprehensive Cancer Center, Duarte, California.

Submitted December 11, 2013; accepted for publication June 24, 2014.

Dr. Hurria has disclosed that she is a PI on investigator-initiated research funded by GlaxoSmithKline and Celgene Corporation; she is a consultant and advisory board member for GTx, Inc.; and is a consultant for Seattle Genetics, Inc. and Boehringer Ingelheim $\mathrm{GmbH}$. The remaining authors have disclosed that they have no financial interests, arrangements, affiliations, or commercial interests with the manufacturers of any products discussed in this article or their competitors. This research received support from the National Cancer Institute of the National Institutes of Health under grant number P30CA033572. The content of this report is solely the responsibility of the authors and does not necessarily represent the official views of the National Institutes of Health.

Correspondence: Carolyn E. Behrendt, PhD, City of Hope Comprehensive Cancer Center, 1500 East Duarte Road, Duarte, CA 91010. E-mail: cbehrendt@coh.org serves to inform institutional efforts to eliminate disparity in clinical trial participation. ${ }^{2}$

Studies of cooperative group trials ${ }^{3-5}$ have concluded that African American, ${ }^{3-5}$ Asian, ${ }^{4,5}$ and Hispanic ${ }^{3-5}$ patients are accrued at lower rates than non-Hispanic white patients. However, systematic reviews ${ }^{6,7}$ have concluded that the quality of studies on barriers to participation in cancer clinical trials is poor, with many threats to internal and external validity (eg, selection bias, poor survey design, hypothetical vs documented participation). ${ }^{7}$ Uncontrolled confounding by socioeconomic factors threatens the validity of reported associations with race/ethnicity. ${ }^{3-6}$ According to a national study of patients with breast cancer aged 65 years or older, ${ }^{8}$ after age and county economic attributes are accounted for, African and Asian patients are no less likely and Hispanic patients are nearly 3 times more likely to participate in trials than Caucasian patients.

When evaluating disparities in clinical trial accrual, potential confounding factors are not limited to socioeconomic characteristics of the patient or her community. Clinical factors, such as younger age,, 10 more advanced stage of disease, ${ }^{9,10}$ newly diagnosed status, ${ }^{10}$ good performance status, ${ }^{10}$ and having an oncologist who is a principal investigator of breast cancer trials, ${ }^{11}$ promote the likelihood that a patient with breast cancer will be offered a trial. The treatment setting also plays a role: centers with approved cancer programs (ie, comprehensive cancer centers) tend to promote accrual onto clinical trials more than other centers. ${ }^{5}$

To understand the extent to which socioeconomic and clinical factors may obscure disparity in accrual, the authors identified all women with breast cancer treated by medical oncologists at City of Hope Comprehensive Cancer Center in recent years; classified them per birthplace and self-reported race/ethnicity as primarily of African, Asian, Latin American, Eastern European, 


\begin{tabular}{|c|c|c|c|}
\hline Characteristics & Total $^{\mathrm{a}}$ (Column \%) & Accrued $^{\mathrm{b}}($ Row \%) & $P^{c}$ \\
\hline Ancestry, per birthplace and self-reported race/ethnicity & & & .08 \\
\hline African & $78(5.3)$ & $24(30.8)$ & \\
\hline Asian & $242(16.3)$ & $66(27.3)$ & \\
\hline Eastern European & $20(1.3)$ & $4(20.0)$ & \\
\hline Latin American & $420(28.3)$ & $138(32.9)$ & \\
\hline Middle Eastern & $96(6.5)$ & $18(18.8)$ & \\
\hline Other Caucasian ${ }^{d}$ & $626(42.2)$ & $196(31.3)$ & \\
\hline Primary language & & & .02 \\
\hline English & $1246(84.1)$ & $377(30.3)$ & \\
\hline Spanish & $138(9.3)$ & $50(36.2)$ & \\
\hline Other & $98(6.6)$ & 19 (19.4) & \\
\hline Immigrant & & & .60 \\
\hline Yes & $570(38.5)$ & $167(29.3)$ & \\
\hline No & $912(61.5)$ & $279(30.6)$ & \\
\hline Age $(y)$ & & & $<.0001$ \\
\hline $22-39$ & $120(8.1)$ & $43(35.8)$ & \\
\hline $40-49$ & $362(24.4)$ & $125(34.5)$ & \\
\hline $50-59$ & $467(31.5)$ & $152(32.6)$ & \\
\hline $60-69$ & $330(22.3)$ & $98(29.7)$ & \\
\hline $70-79$ & $141(9.5)$ & $22(15.6)$ & \\
\hline 80-95 & $62(4.2)$ & $6(9.7)$ & \\
\hline Health insurance & & & $<.01$ \\
\hline Medicaid/none & $413(27.9)$ & $145(35.1)$ & \\
\hline Medicare or private insurance & 1069 (72.1) & $301(28.2)$ & \\
\hline Marital status & & & .16 \\
\hline Single & $235(15.9)$ & $83(35.3)$ & \\
\hline Married & $915(61.7)$ & $274(30.0)$ & \\
\hline Separated & $30(2.0)$ & $11(36.7)$ & \\
\hline Divorced & $155(10.5)$ & $45(29.0)$ & \\
\hline Widowed & $143(9.7)$ & $32(22.4)$ & \\
\hline Unknown & $4(0.3)$ & $1(25.0)$ & \\
\hline Median household income within zip code & & & .62 \\
\hline$<\$ 45,500$ & $214(14.4)$ & $68(31.8)$ & \\
\hline$\$ 45,500-\$ 65,499$ & $554(37.4)$ & $163(29.4)$ & \\
\hline$\$ 65,500-\$ 85,499$ & $487(32.9)$ & $140(28.8)$ & \\
\hline$\geq \$ 85,500$ & $227(15.3)$ & $75(33.0)$ & \\
\hline $\begin{array}{l}\text { Percentage of race/ethnicity-matched women } \geq 25 \text { y in zip } \\
\text { code who lack high school education }\end{array}$ & & & .03 \\
\hline$<5 \%$ & $309(20.9)$ & $98(31.7)$ & \\
\hline $5 \%$ to $<30 \%$ & $894(60.3)$ & $248(27.7)$ & \\
\hline$\geq 30 \%$ & $279(18.8)$ & $100(35.8)$ & \\
\hline Distance from zip code to cancer center & & & .13 \\
\hline$<5$ miles & $105(7.1)$ & $25(23.8)$ & \\
\hline 5 to $<10$ miles & $261(17.6)$ & $79(30.3)$ & \\
\hline 10 to $<20$ miles & $447(30.2)$ & $140(31.3)$ & \\
\hline \multicolumn{4}{|l|}{$\geq 20$ miles: } \\
\hline Within Los Angeles or contiguous counties & $620(41.8)$ & $194(31.3)$ & \\
\hline In more distant counties & $49(3.3)$ & $8(16.3)$ & \\
\hline
\end{tabular}

Abbreviations: ER, estrogen receptor; HER2, HER2/neu; PR, progesterone receptor. ${ }^{\mathrm{a}} \mathrm{N}=1482$.

${ }^{\mathrm{b}} \mathrm{N}=446$.

' $P$ value from univariate chi-square testing.

dEnglish-speaking, non-Hispanic Caucasian patients born in the United States, Canada, Great Britain, Western Europe, or to such parents living in Asia or South Africa. 
Socioeconomic Factors and Disparity in Trial Accrual

\begin{tabular}{|c|c|c|c|}
\hline Characteristics & Total $^{\mathrm{a}}$ (Column \%) & Accrued $^{b}$ (Row \%) & $P^{c}$ \\
\hline Tumor stage & & & $<.0001$ \\
\hline 1 & $406(27.4)$ & $90(22.2)$ & \\
\hline II & $589(39.7)$ & $162(27.5)$ & \\
\hline III & $327(22.1)$ & $124(37.9)$ & \\
\hline IV & $160(10.8)$ & $70(43.8)$ & \\
\hline ER status & & & $<.0001$ \\
\hline Positive & $1092(73.7)$ & $296(27.1)$ & \\
\hline Negative & $384(25.9)$ & $150(39.1)$ & \\
\hline Unavailable & $6(0.4)$ & $0(0)$ & \\
\hline PR status & & & .02 \\
\hline Positive & $906(61.1)$ & $249(27.5)$ & \\
\hline Negative & $560(37.8)$ & $192(34.3)$ & \\
\hline Unavailable & $16(1.1)$ & $5(31.3)$ & \\
\hline HER2 status & & & .13 \\
\hline Positive & $336(22.7)$ & $116(34.5)$ & \\
\hline Negative & $1020(68.8)$ & $295(28.9)$ & \\
\hline Unavailable & $126(8.5)$ & $35(27.8)$ & \\
\hline ER/PR/HER2 status & & & .001 \\
\hline ER-, PR-, HER2- & $206(13.9)$ & $76(36.9)$ & \\
\hline ER-, PR-, HER2 unavailable & $157(10.6)$ & $62(39.5)$ & \\
\hline $\mathrm{ER}+$ and/or PR+ & $1114(75.2)$ & $308(27.5)$ & \\
\hline ER, PR, HER2 all unavailable & $5(0.3)$ & $0(0)$ & \\
\hline Years since diagnosis & & & .08 \\
\hline$<1$ & $460(31.0)$ & $126(27.4)$ & \\
\hline 1 & $794(53.6)$ & $243(30.6)$ & \\
\hline 2 & $68(4.6)$ & $17(25.0)$ & \\
\hline$\geq 3$ & $160(10.8)$ & $60(37.5)$ & \\
\hline Calendar year & & & .003 \\
\hline 2004 & $202(13.6)$ & $76(37.6)$ & \\
\hline 2005 & $239(16.1)$ & $75(31.4)$ & \\
\hline 2006 & $247(16.7)$ & $77(31.2)$ & \\
\hline 2007 & $223(15.1)$ & $62(27.8)$ & \\
\hline 2008 & $254(17.1)$ & $86(33.9)$ & \\
\hline 2009 & $317(21.4)$ & $70(22.1)$ & \\
\hline Oncologist's role in breast cancer trials & & & $<.0001$ \\
\hline Principal investigator & $769(51.9)$ & $297(38.6)$ & \\
\hline Not a principal investigator & $713(48.1)$ & $149(20.9)$ & \\
\hline Duration of oncologist's practice at this institution & & & $<.0001$ \\
\hline$<5$ y & $795(53.6)$ & $195(24.5)$ & \\
\hline$\geq 5$ y & $687(46.4)$ & $251(36.5)$ & \\
\hline Oncologist fluent in patient's primary language & & & .95 \\
\hline Yes, English & $1233(83.2)$ & $371(30.1)$ & \\
\hline Yes, language other than English & $22(1.5)$ & $6(27.3)$ & \\
\hline No & $227(15.3)$ & $69(30.4)$ & \\
\hline
\end{tabular}

Abbreviations: ER, estrogen receptor; HER2, HER2/neu; PR, progesterone receptor.

${ }^{\mathrm{a}} \mathrm{N}=1482$.

${ }^{\mathrm{N}} \mathrm{N}=446$.

c $P$ value from univariate chi-square testing.

${ }^{\mathrm{d} E n g l i s h-s p e a k i n g, ~ n o n-H i s p a n i c ~ C a u c a s i a n ~ p a t i e n t s ~ b o r n ~ i n ~ t h e ~ U n i t e d ~ S t a t e s, ~ C a n a d a, ~ G r e a t ~ B r i t a i n, ~ W e s t e r n ~ E u r o p e, ~ o r ~ t o ~ s u c h ~ p a r e n t s ~ l i v i n g ~ i n ~ A s i a ~}$ or South Africa. 
Middle Eastern, and other Caucasian ancestry; followed them for accrual onto therapeutic trials; and evaluated the association between ancestry and accrual, before and after accounting for socioeconomic and clinical factors.

\section{Methods}

\section{Subjects}

Because the study used deidentified data, the City of Hope Institutional Review Board granted a waiver of informed consent. Subjects were consecutive women with breast cancer (stage I-IV) first treated by a medical oncologist at the institution during 2004 through 2009, an era that was determined by the study cohort. (Patients seen only once for a second opinion were by definition never accrued onto a trial and thus were ineligible for the study. Out-of-state residents were too few $[n=5]$ to permit their inclusion as a subgroup.) If a subject had synchronous breast tumors, only characteristics of the more advanced or hormone-negative tumor were studied. In cases of metachronous tumors, only characteristics of the first tumor were studied.

\section{Definitions and Data Sources}

The study's end point was accrual onto a trial of adjuvant, neoadjuvant, or nonadjuvant treatment for breast cancer from 2004 through 2010; this information was obtained from the center's protocol accrual database. Breast cancer trials were continuously available during the study. By definition, accrued subjects received at least one dose of assigned treatment. There was no matching of accrued and nonaccrued patients.

Self-reported data on race, Hispanic ethnicity, primary language, and birthplace were routinely collected on admission via written questionnaire. Infrequently, it was necessary to abstract missing data on subjects' primary language or place of birth from the medical record (ie, from notation about self-reported nationality, linguistic preference, or use of a translator, such as staff or family member). From race, ethnicity, and birthplace, subjects were assigned a primary ancestry for this study using the following hierarchy: African (per primary racial identity), Asian (per primary racial identity), Middle Eastern (per birthplace), Eastern European (per birthplace), Latin American (per ethnicity), and the referent category of "other Cauca- sian" (per ethnicity [non-Hispanic], race [white], and birthplace [North America or Western Europe]). The few patients born abroad to non-Hispanic white parents in Asia or South Africa were classified as "other Caucasian." No subject identified herself as Native American or Pacific Islander.

Zip code-level data on income and education were obtained from the United States Census Bureau's American Community Survey, 2007-2011.12 For "median household income during the past 12 months," data were expressed in 2011-adjusted dollars. For educational attainment, percentage lacking a high school education among women aged 25 years or older of the subject's own race/ethnicity was studied. Subjects $(n=22)$ residing in zip codes that were too small to generate these data were assigned the sample's median of "median household income" and the race/ethnicity-specific median of "percentage of adult females lacking high school education."

\section{Statistical Analysis}

The study's primary hypothesis was that accrual onto breast cancer trials varies by ancestry, the referent category being patients of "other Caucasian" ancestry. Covariates considered in the generalized estimating equations of binary outcome were characteristics relating to the patient (primary language, immigrant status, age at first visit, marital status, type of health insurance), zip code (distance to cancer center, median household income, race/ethnicityspecific percentage of adult women without high school education), tumor (stage, hormone [estrogen, progesterone] receptor status, HER2/neu status, calendar year of first visit, time since diagnosis), and the oncologist (status as principal investigator [PI] of any therapeutic trial of breast cancer treatment, time in practice at the institution, fluency in the patient's primary language). The first model ignored all covariates; the second model took into account age and all covariates (tumor and oncologist characteristics, patient- and zip code-level socioeconomic factors, any interactions between covariates) that improved the model's fit to the observed data. Both models took into account correlation among subjects treated by the same oncologist (intrapractice clustering of patients) using an independent type of correlation matrix structure. For each model, overall study error (potentially inflated from testing multiple types of ancestry) was maintained at less than $5 \%$ by using the Holm-Bonferroni adjustment to $P$ values. ${ }^{13}$ 
Socioeconomic Factors and Disparity in Trial Accrual

\section{Results}

The subjects were 1482 women with breast cancer who presented for treatment at age $55.7 \pm 12.4$ years (Table 1). Of these, 446 (30.1\%) were accrued onto a therapeutic trial during the observation period. Most subjects $(70.0 \%)$ who participated in a trial were accrued onto relatively large trials (11 protocols that enrolled 10-126 current subjects each); 8 of those protocols offered informed consent documents in Spanish. In contrast, small-scale trials (55 protocols that enrolled 1-8 current subjects each) rarely obtained Spanish translations of consent documents.

Before any covariates were considered (Table 2, see column "Model Without Covariates"), accrual did not vary significantly by ancestry, except for a deficit among patients of Middle Eastern ancestry. In contrast, after accounting for socioeconomic and clinical covariates (Table 2, see column "Model With Covariates"), significant deficits in accrual became apparent for patients in all nonreferent categories of ancestry (African, Asian, Eastern European, Latin American, Middle Eastern). Moreover, these deficits differed from each other: for all possible contrasts between deficits, unadjusted $P$ value was .02 or less. All socioeconomic and clinical covariates contributed to the model's fit to the observed data except oncologist's fluency in the patient's primary language, which was the only covariate that was dropped from the final model.

\section{Discussion}

As demonstrated by the current study, disparity in accrual onto cancer clinical trials may go unrecognized unless socioeconomic and clinical factors are taken into account. In this study, adjustment for socioeconomic factors does not eliminate associations with race/ethnicity, as reported by others, ${ }^{8,14,15}$ but instead helps reveal ancestry-related disparities that otherwise would remain obscure. Also helpful to that end was statistical methodology that accounts for correlation among patients treated by the same oncologist.

The proportion of current subjects accrued onto a trial $(30 \%)$ seems similar to reports of studies of patients with breast cancer at other comprehensive cancer centers $\left(34 \%{ }^{10}\right.$ and $\left.18 \%{ }^{16}\right)$. In all 3 studies, accrual onto trials varied by age; variation in age distribution across study samples makes direct comparisons between studies difficult.
Contrary to expectation, the authors found that lack of fluency in English alone does not constitute a barrier to accrual but instead exacerbates the barrier associated with increasing age at first visit. That age barrier displays no threshold corresponding to the elderly; instead, after age 40 years, age has a gradual adverse effect on accrual, suggesting that subjects are offered trials based on functional criteria without regard to chronologic age. Also contrary to expectation, the authors found that immigrant status promotes rather than deters accrual and that accrual does not vary based on whether the physician is able to speak the patient's primary language.

Consistent with findings of an earlier report, ${ }^{11}$ the authors found that accrual is enhanced when the subject's physician is a PI for breast cancer trials. Contrary to previous reports of below-average ${ }^{8}$ or average ${ }^{5}$ accrual of Medicaid-insured patients, the authors observed their accrual to be heightened, but only when the oncologist was a PI. Otherwiseinsured patients also experienced heightened accrual with PIs, whom the authors found to enroll subjects without regard for years since diagnosis. In contrast, non-PI oncologists enroll subjects without regard for their insurance status but do preferentially accrue patients who are at least 3 years beyond diagnosis.

Previous studies have associated accrual with higher income and other measures of socioeconomic status ${ }^{5,14}$ and inversely with local poverty and unemployment. ${ }^{8}$ Similarly, in the current study, accrual increases with median household income within the subject's zip code, but only in the upper half of the income distribution. At the same time, however, accrual in the current study is favorably associated with certain measures of socioeconomic disadvantage (Medicaid eligibility; low educational attainment among similar women in the subject's zip code), independent of income. These findings show that those socioeconomic factors apparently promote the offer and/or acceptance of a clinical trial.

According to the authors' analysis, the deficits in accrual currently observed by ancestry cannot be attributed to lack of fluency in English, language gap between physician and patient, or the other socioeconomic and clinical factors studied. Instead, a more likely explanation for disparity in accrual may be differing levels of health literacy, "the capacity to obtain, process, and understand basic health information and services needed to make appropriate 


\begin{tabular}{|c|c|c|c|c|}
\hline & \multicolumn{2}{|c|}{ Model Without Covariates } & \multicolumn{2}{|c|}{ Model With Covariates } \\
\hline & $\begin{array}{l}\text { Odds Ratio } \\
(95 \% \mathrm{Cl})\end{array}$ & $\begin{array}{l}\text { Holm- } \\
\text { Adjusted } \\
P \text { Value }\end{array}$ & $\begin{array}{l}\text { Odds Ratio } \\
(95 \% \mathrm{Cl})\end{array}$ & $\begin{array}{l}\text { Holm-Adjusted } \\
P \text {-Value }\end{array}$ \\
\hline \multicolumn{5}{|l|}{$\begin{array}{l}\text { Primary ancestry, per birthplace and self-reported race/ } \\
\text { ethnicity }\end{array}$} \\
\hline African & $0.98(0.80-1.19)$ & 1.00 & $0.70(0.54-0.92)$ & .011 \\
\hline Asian & $0.82(0.65-1.04)$ & .39 & $0.49(0.42-0.58)$ & $<.001$ \\
\hline Eastern European & $0.55(0.25-1.19)$ & .39 & $0.27(0.12-0.60)$ & 0.003 \\
\hline Latin American & $1.07(0.84-1.38)$ & 1.00 & $0.56(0.42-0.76)$ & $<.001$ \\
\hline Middle Eastern & $0.51(0.33-0.78)$ & .01 & $0.35(0.25-0.50)$ & $<.001$ \\
\hline Other Caucasian & 1.00 & & 1.00 & \\
\hline \multicolumn{5}{|l|}{ Clinical Covariates: } \\
\hline \multicolumn{5}{|l|}{ Stage of tumor } \\
\hline 1 & & & 1.00 & \\
\hline II & & & $1.24(0.99-1.55)$ & \\
\hline III & & & $2.07(1.57-2.74)$ & \\
\hline IV & & & $3.11(2.31-4.19)$ & \\
\hline \multicolumn{5}{|l|}{ Calendar year of first visit, by ER status ${ }^{\mathrm{a}}$} \\
\hline 2004, any ER status & & & $2.45(1.73-3.48)$ & \\
\hline 2005-2007, any ER status & & & $1.39(1.07-1.80)$ & \\
\hline 2008, ER+ & & & $1.39(1.07-1.80)$ & \\
\hline 2008, ER- & & & $4.25(2.94-6.15)$ & \\
\hline 2009, any ER status & & & 1.00 & \\
\hline \multicolumn{5}{|l|}{ Physician's duration of practice at institution } \\
\hline$<5 y$ & & & $0.82(0.70-0.96)$ & \\
\hline$\geq 5 y$ & & & 1.00 & \\
\hline \multicolumn{5}{|c|}{ Physician's role in breast cancer trials, by patient's health insurance and time since diagnosis ${ }^{a}$} \\
\hline $\mathrm{PI}$, Medicaid/uninsured patient, any time since diagnosis & & & $3.52(2.08-5.97)$ & \\
\hline PI, Medicare/insured patient, any time since diagnosis & & & $2.32(1.66-3.25)$ & \\
\hline \multicolumn{5}{|l|}{ Not a Pl, any insurance status: } \\
\hline Diagnosed $\geq 3$ y before first visit to this center & & & $2.27(1.39-3.69)$ & \\
\hline Diagnosed $<3$ y before first visit to this center & & & 1.00 & \\
\hline \multicolumn{5}{|l|}{ Socioeconomic Covariates: } \\
\hline \multicolumn{5}{|l|}{ Age at first visit to this center, by primary language $\mathrm{e}^{\mathrm{a}}$} \\
\hline Per (year of age beyond $39 \mathrm{y})^{2} / 100$, English & & & $0.95(0.93-0.97)$ & \\
\hline Per (year of age beyond $39 \mathrm{y})^{2} / 100$, not English & & & $0.87(0.84-0.91)$ & \\
\hline \multicolumn{5}{|l|}{ Immigrant } \\
\hline Yes & & & $1.34(1.05-1.71)$ & \\
\hline No & & & 1.00 & \\
\hline \multicolumn{5}{|l|}{ Divorced } \\
\hline Yes & & & $0.75(0.58-0.98)$ & \\
\hline No & & & 1.00 & \\
\hline \multicolumn{5}{|l|}{ Residential zip code } \\
\hline Within the local or contiguous county & & & 1.00 & \\
\hline Within a more distant county & & & $0.33(0.17-0.65)$ & \\
\hline \multicolumn{5}{|l|}{ Median household income of zip code } \\
\hline Per $(\$ 1000 \text { In Excess of } \$ 66,000)^{2}$ & & & $1.03(1.02-1.05)$ & \\
\hline Per $(\$ 1000 \text { In Excess of } \$ 66,000)^{2} / 100$ & & & $0.95(0.93-0.98)$ & \\
\hline $\begin{array}{l}\text { Educational attainment of race/ethnicity-matched women } \\
\text { Per } 1 \% \text { of women }>25 \text { y lacking high school education }\end{array}$ & in zip code & & $1.02(1.00-1.03)$ & \\
\hline
\end{tabular}

Abbreviations: ER, estrogen receptor; PI, principal investigator.

aThe categorization of risk factors was dictated by significant interaction between the variables listed. 
health decisions." ${ }^{17}$ Limited health literacy can result in less awareness of and/or willingness to participate in clinical trials; one or both of these factors have been associated with Asian, African American, and Hispanic ethnicity among patients attending oncology clinics. ${ }^{18,19}$ Additional patient characteristics that may contribute to disparity in trial accrual are belief that the disease's outcome is inevitable or "in God's hands," 15 preference against active decisionmaking $^{20}$ or against undergoing treatment, ${ }^{13,21}$ and weight given to perceived personal benefit versus altruism. ${ }^{13,22,23}$

Limitations of the current study include its setting at a single cancer center, data on income and education being available for the patient's zip code rather than for the patient herself, and lack of data on comorbidities, ${ }^{14}$ performance status, ${ }^{10}$ and health literacy. In addition, offers and acceptances of trials were not tracked prospectively, and whether any subjects participated in therapeutic trials elsewhere could not be ascertained. Nevertheless, these limitations are routinely encountered when cancer centers monitor patient accrual onto therapeutic trials.

Further study is needed to identify and address the specific barriers to trial accrual that disproportionately affect "minority" women with breast cancer. From such research, clinical investigators may learn how to promote trial accrual among all eligible patients, regardless of their ancestry.

\section{Acknowledgments}

The authors wish to thank Yan Shen, MS, Leanne Goldstein, DrPH, and Sharla Moore, MPH, for assistance with data collection, and Linda Brown, MLS, for helpful discussion about health literacy.

\section{References}

1. Inclusion of women and minorities as participants in research involving human subjects - policy implementation page. National Institutes of Health Web site. Available at: http://grants.nih.gov/grants/funding/ women_min/women_min.htm. Accessed November 30, 2013.
2. Murthy VH, Krumholz HM, Gross CP. Participation in cancer clinical trials: race-, sex-, and age-based disparities. JAMA 2004;291:2720-2726.

3. Anwuri VV, Hall LE, Mathews $K$, et al. An institutional strategy to increase minority recruitment to therapeutic trials. Cancer Causes Control 2013;24:1797-1809.

4. Stewart JH, Bertoni AG, Staten JL, et al. Participation in surgical oncology clinical trials: gender-, race/ethnicity-, and age-based disparities. Ann Surg Oncol 2007;14:3328-3334.

5. Sateren WB, Trimble EL, Abrams J, et al. How sociodemographics, presence of oncology specialists, and hospital cancer programs affect accrual to cancer treatment trials. J Clin Oncol 2002;20:2109-2117.

6. Ford JG, Howerton MW, Lai GY, et al. Barriers to recruiting underrepresented populations to cancer clinical trials: a systematic review. Cancer 2008;112:228-242.

7. Fayter DA, McDaid C, Eastwood A. A systematic review highlights threats to validity in studies of barriers to cancer trial participation. J Clin Epidemiol 2007;60:990-1001.

8. Gross CP, Filardo G, Mayne ST, et al. The impact of socioeconomic status and race on trial participation for older women with breast cancer. Cancer 2005; 103:483-491.

9. Kemeny MM, Peterson BL, Kornblith AB, et al. Barriers to clinical trial participation by older women with breast cancer. J Clin Oncol 2003;21:2268-2275.

10. Simon MS, Du W, Flaherty L, et al. Factors associated with breast cancer clinical trials participation and enrollment at a large academic medical center. J Clin Oncol 2004;22:2046-2052.

11. Mannel RS, Walker JL, Gould N, et al. Impact of individual physicians on enrollment of patients into clinical trials. Am J Clin Oncol 2003;26:171173.

12. United States Census Bureau. American FactFinder.Available at: http:// factfinder2.census.gov. Accessed November 12, 2013.

13. Holm S. A simple sequentially rejective multiple test procedure. Scand J Stat 1979;6:65-70.

14. Unger JM, Hershman DL, Albain KS, et al. Patient income level and cancer clinical trial participation. J Clin Oncol 2013;31:536-542.

15. Advani AS, Atkeson B, Brown CL, et al. Barriers to the participation of African-American patients with cancer in clinical trials: a pilot study. Cancer 2003;97:1499-1506.

16. Kanarek NF, Tsai HL, Metzger-Gaud S, et al. Geographic proximity and racial disparities in cancer clinical trial participation. J Natl Compr Canc Netw 2010;8:1343-1351.

17. Davis TC, Williams MV, Marin E, et al. Health literacy and cancer communication. CA Cancer J Clin 2002;52:134-149.

18. Lara PN Jr, Paterniti DA, Chiechi C, et al. Evaluation of factors affecting awareness of and willingness to participate in cancer clinical trials. J Clin Oncol 2005;23:9282-9289.

19. Paterniti DA, Chen MS Jr, Chiechi C, et al. Asian Americans and cancer clinical trials: a mixed-methods approach to understanding awareness and experience. Cancer 2005;104:3015-3024.

20. Ellis PM, Butow PN, Tattersall $\mathrm{MH}$, et al. Randomized clinical trials in oncology: understanding and attitudes predict willingness to participate. J Clin Oncol 2001;19:3554-3561.

21. Liang W, Wang JH, Chen MY, et al. Developing and validating a measure of Chinese cultural views of health and cancer. Health Educ Behav 2008;35:361-375.

22. Jenkins V, Farewell V, Farewell D, et al. Drivers and barriers to patient participation in RCTs. Br J Cancer 2013;108:1402-1407.

23. Wright JR, Whelan TJ, Schiff S, et al. Why cancer patients enter randomized clinical trials: exploring the factors that influence their decision. J Clin Oncol 2004;22:4312-4316. 